\title{
Analysing Poverty in Nigeria through Theoretical Lenses
}

\author{
Victoria Voelwoen Danaan ${ }^{1}$ \\ ${ }^{1}$ University of Salford, Manchester, United Kingdom \\ Correspondence: Victoria Voelwoen Danaan, University of Salford, Manchester, United Kingdom. E-mail: \\ victoriadanaan@yahoo.com; v.danaan@edu.salford.ac.uk
}

Received: August 8, 2017

doi:10.5539/jsd.v11n1p20
Accepted: October 13, $2017 \quad$ Online Published: January 30, 2018

URL: https://doi.org/10.5539/jsd.v11n1p20

\begin{abstract}
Various indicators suggest that poverty is a major obstacle to Nigeria's socio-economic development. Poverty has persisted and several interventions have failed to yield significant improvement in Nigeria's Human Development Index even in periods of economic growth. Plagued with the challenges of unemployment crises, climate change, conflict, fragility and violence, Nigeria (the most populous country in Africa) stands at a grave risk if poverty is not tackled. This paper explores seven theories of poverty in literature: The Culture of Poverty, Individual Deficiency Theory, Progressive Social Theory, Geographical Disparities Theory, Cyclical Interdependence Theory, Poverty Individualisation and the Theory of Social Exclusion /Cumulative Disadvantage. It reviews these theories by employing a qualitative and descriptive research approach in order to broaden the understanding of the complexities of the phenomenon of poverty from a global worldview and examine how these relate to the nature of poverty in Nigeria. It corroborates the fact that poverty in Nigeria is complex and multidimensional in its conceptualization and measurement, encompassing economic, social, cultural and psychological indicators. The paper therefore attempts to explore the phenomenon of poverty within the Nigerian context by examining these theoretical paradigms. It suggests an understanding of underlying causal factors of poverty in designing pro-poor programmes and a hydra-headed approach to tackle its menace effectively and progressively. It argues that poverty reduction is realizable by empowering people to develop resilience to cope and overcome it within the scope of their resources and capabilities.
\end{abstract}

Keywords: poverty, Nigeria, income, development, theory

\section{Introduction}

Poverty has remained a threat and challenge to humanity in all ramifications. It is complex, multidimensional and multifaceted with manifestations in the economic, social, political, environmental and every realm of human existence. The conceptualization of poverty over the years is changing with emerging perspectives in different contexts. Bhalla and Lapeyre (2016) relate it to the concept of social exclusion as an emerging phenomenon in both developed and developing contexts. Bradshaw and Main (2016) discuss child poverty, addressing how the well-being of children is affected by indices of poverty. Room (2016) analyses the new poverty in the European community, indicating the existence of poverty in even the most advanced societies. Poverty remains a significant topic of discourse in Africa (Beegle, Christiaensen, Dabalen, \& Gaddis, 2016; Grootaert, 1995). Poverty has been linked to climate vulnerability (Thornton et al., 2006), social protection (Barrientos \& Hulme, 2016) and gender issues (Shah, 2016). Historically, scholars (e.g. Feagin, 1972; Lewis, 1971; Myrdal, 1968) wrote interesting thesis on diverse aspects of poverty. Ajakaiye and Adeyeye (2001) give a historical background of these changing perspectives from a focus on income indicators in the 1960s to inclusion of non-monetary indicators in the 1990s and beyond. Poverty is listed as a risk factor in coping with health challenges (Pearson, 2015). Poverty has multiplier effects and linkages such that lack of access to resources can affect health status, life expectancy, security, education and relationships. Efforts are being intensified globally through reforms, interventions and sustainable development goals to tackle poverty and improve living standards. Nations are categorised on the scale of development based on indices that have direct bearing on poverty.

The challenges of poverty in Nigeria have attracted the attention of successive administrations. However, it remains a paradox-poverty in the midst of plenty and rising in periods of economic growth (Omoyibo, 2013). This may be true to the extent that Nigeria is endowed with human and natural resources and has had an increasing national income; yet, a larger section of her population languishes in poverty due uneven distribution and allocation of income and wealth (Aigbokhan, 1998; Alesina \& Perotti, 1996; Lipton, 1980). Dauda (2017) 
notes that poverty in Nigeria differs with the pattern in many other countries given that even with the economic growth recorded, poverty is still on the increase with the North- West and North -East geopolitical zones leading in the poverty indices. This situation is at variance with the experiences of developing countries in Europe, America and Asia where economic growth results in poverty reduction. This lends credence to the long-standing assumption that the relationship between poverty, economic growth and development is not even.

Several poverty reduction policies and programmes have been adopted to alleviate or eradicate poverty in Nigeria. Some of these were sectoral interventions but their overarching goal was poverty reduction (Oshewolo, 2010). Notable poverty reduction programmes pursued in Nigeria by include:

-Operation Feed the Nation (Agriculture)

- Free and Compulsory Primary Education (Education)

- Green Revolution (Agriculture)

-Low Cost Housing (Housing)

-River Basin Development Authorities (Agriculture)

-National Agricultural Land Development Authority (Agriculture)

-Agricultural Development Programmes (Agriculture)

- Agricultural Credit Guarantee Scheme (Agriculture)

-Strategic Grains, Reserves Program (Agriculture)

-Rural Electrification Scheme (Rural Development)

-Rural Banking Programme (Rural development and financial inclusion)

-Family Economic Advancement Programme (Poverty Alleviation)

-Better Life for Rural Women (Women Empowerment)

-Family Support Programme (Poverty Alleviation)

-National Directorate of Employment (Job Creation)

-Mass Transit Programme (Transport)

-Guinea Worm Eradicating Programme (Health)

-Petroleum Trust Fund (Education, Health, Rural Development)

-National Poverty Eradication Programme (Poverty Alleviation)

-National Economic Empowerment and Development Strategy (NEEDS)

Even with this wide array of programmes, poverty alleviation has remained a mirage in Nigeria. Arisi-Nwugballa, Elom, and Onyeizugbe (2016) opine that the Structural Adjustment Programme (SAP) and post-SAP eras in Nigeria were characterized by active government intervention in poverty alleviation initiatives with insignificant improvement in living standards. Ihonvbere (1993) disputes this claim by asserting that SAP removed all the social benefits and welfare services previously enjoyed by the generality of the masses. John C Anyanwu (1992, p. 5) also berates SAP for promoting the emergence of an 'unregulated and dependent capitalist development model, while allowing only a supportive role for the government in a refurbished economic environment of highly reduced government ownership and control of enterprises'. He suggests that SAP allowed poverty and inflation to flourish by the removal of subsidies on petroleum products and fertiliser, trade liberalisation, deregulation, privatisation and commercialisation.

Many reasons have been given for the abysmal performance of poverty alleviation initiatives in Nigeria- poor design and implementation, policy inconsistencies and discontinuity, poor funding and corruption (Aigbokhan, 2008; Arisi-Nwugballa et al., 2016; Dauda, 2017; Elumilade, Asaolu, \& Adereti, 2006) . Arisi-Nwugballa et al. (2016) note that poverty alleviation initiatives tend to be geared towards providing financial credit and grants to drive the development of Micro, Small and Medium Enterprises (MSMEs) leading to job creation and capacity utilization. Some of these interventions enhanced the incomes of the target beneficiaries engaged in MSMEs but this could not be sustained due to obstacles such as the high cost of running businesses, infrastructural decay and competition caused by the proliferation of cheaper imported substitutes.

The articulation of government policies and programmes to spur innovations, entrepreneurship, infrastructural development and improved welfare has proven to be inadequate to address the poverty situation in Nigeria. This 
paper contributes to knowledge in exploring the theories of poverty in literature in order to broaden the understanding of the complexities of the phenomenon of poverty in Nigeria. It employs qualitative and descriptive analyses of the theories from a global worldview and examines how these are applicable to the Nigerian poverty situation.

\subsection{The Concept of Poverty}

There is no consensus on a standard definition of poverty despite its universality and the enormous literature on it (Laderchi, Saith, \& Stewart, 2003, 2006). There are divergent views on its nature, how to determine whether it is rising or falling and the understanding of transition from being 'non-poor' into the poverty trap. Deaton (2002, p. 4) captures this dilemma accurately in seeking to know the true representation of global poverty;

Real progress has been made in reducing poverty in recent years, particularly in India and China. However, there is still much uncertainty about the numbers. Using the same data, two reports released less than two years apart by the World Bank reached apparently different conclusions on whether world poverty was going up or down. How can we know whether the world poverty counts are accurate?

Debates persist because poverty has both tangible and intangible indicators. Callan and Nolan (1991) observe that one challenge confronting researchers and policy makers is the identification of the poor and measuring the extent of their poverty. Given the complexity of the issues, the best introduction to poverty measurement is through the multifaceted nature of the phenomenon and the different concepts of it' (Lok-Dessallien, 1999, p. 2). In spite of the controversies surrounding its conceptualization, it is generally agreed that poverty has adverse effects on individuals and communities; it breeds social exclusion, isolation fear, distress and deprivations (Backwith, 2015). The poor tend to be powerless and voiceless; they live in sub-standard environments with low incomes, inadequate social amenities and opportunities for improved well-being. Poverty may lead to loss of self-confidence, self- actualization, self-fulfilment, lack of good orientation and abandonment of cultural values and heritage such that people are ashamed of their cultural and racial identity (Commins, 2004; Jencks, 1992; Porter \& Washington, 1979; Shah, 2016) . It also manifests in ethics and morality where shallow intellectualism prevails, and people do everything to achieve their selfish goals (Abimuku, 2006). It makes people lack the capability to function and enjoy the core values of development and sustenance.

Poverty has a strong correlation with income even though the use of income to measure poverty has been strongly disputed (Bak \& Larsen, 2015). The United Nations Development Programme (UNDP) 2002 describes the poor as those who live on less than $\$ 1$ per day. The issues of income inequalities, gender imbalance and rural-urban divide where those who produce wealth are deprived from reaping its benefits have attracted the attention of the international community. Women, rural dwellers and other vulnerable groups who produce the bulk of the world's food get incommensurable rewards for their labour (Abimuku, 2006).

Distinctions have also been made between absolute and relative Poverty (Foster, 1998; Lok-Dessallien, 1999). Absolute or Subsistence Poverty refers to a household's inability to command sufficient income to meet its basic needs for food, shelter, clothing, transportation and education view absolute poverty as a situation of low income and consumption. Income and consumption levels are the parameters in deriving an imaginary Poverty Line (PL) often used as a yardstick for measuring the minimum standard of living. People are considered poor if their measured standard of living in terms of income and consumption falls below the PL (John C Anyanwu, 1997; Callan \& Nolan, 1991). The PL adopted by the World Bank for international comparison is $\$ 1$ per person, per day (Chen \& Ravallion, 2007). Furthermore, individuals below the PL are grouped into two categories; the poor and the extremely poor giving rise to two PLs; the Upper PL (UPL) and the Lower PL (LPL). The poor are individuals whose incomes fall below the UPL but are above the LPL, while the extremely poor are those whose incomes fall below the LPL. Conceptualizing poverty in absolute terms is the most common practice even though it is problematic to determine what constitutes minimum standards of living given varied socio-economic conditions.

Relative poverty is a condition in which an individual or household's income falls short of the average income of the population in the society being considered. Individuals in relative poverty have their resources lower than those possessed by average individuals to the extent that they are excluded from ordinary living patterns, customs and activities. It is context-sensitive and reflects the changing perception of acceptable minimum standard of living. It is also dynamic as it is subject to the needs and demands of a changing society. Sometimes even within a given country, what is luxurious in one period may become essential in another. For instance a 'non poor' person in Chad may be among the extremely poor in Denmark, while electricity, indoor sanitations and pipe borne water are essential in developed countries, they are not perceived as such in poor countries. Lok-Dessallien (1999, p. 3) explains that; 
Poverty measurement has traditionally been dominated by the objective approach. Only relatively recently has the international community as a whole taken a serious interest in measuring subjective poverty. This is mainly because of mounting recognition of the limitations associated with so-called objective indicators and the value of understanding the perspectives of the poor in shaping policies and programmes. As a result, participatory poverty assessment methodologies have been gaining ground.

Subjective Poverty requires a country to define what is considered the minimum adequate standard of living for a given period. It depends on individuals' perceptions about their standard of living.

\section{Measurement of Poverty}

There is no standard parameter for measuring poverty. Generally, quantifying poverty has remained problematic and contentious because of the biases of measurement. Scholars have developed several models for measuring absolute, relative and subjective poverty. It measurement has been classified into two distinct operations; identification of the poor and the aggregation of their poverty characteristics into an overall measure. Absolute Poverty is measured based on the:

\subsection{Head Count/Incidence of Poverty}

This is based on a poverty line(or set of lines) that are established by costing a minimum basket of essential goods for basic human survival, using income, consumption or expenditure data of non- poor households (Lok-Dessallien, 1999). It is usually expressed as the ratio of the number of individuals living below the PL to the total number of people in a given population. It does not indicate the depth or severity of poverty

\subsection{Poverty Gap/Income Shortfall}

It measures the difference between the PL and the average income of the poor expressed as a ratio of the PL (Abimiku, 2006) . It captures the degree of income shortfall below the PL and provides a statement on the level of income needed to raise the income of the poor to the PL. In this sense, it measures the depth of poverty but does not indicate its severity by showing the distribution of the standard of living among the poor.

\subsection{Disparity of Income Distribution}

It encompasses the use of Lorenz Curve (LC) and Gini Coefficient (GC) to present the distribution of poverty (Atkinson, 1970; Gastwirth, 1972; Gastwirth \& Glauberman, 1976). The LC is a graphical representation of the variance in the extent of income distribution. It shows the cumulative percentage of the poor population on the vertical axis and the cumulative percentage of income of the poor on the horizontal axis. The GC measures income distribution based on the Lorenz Curve. It represents the difference of a country's actual income distribution from a theoretically equal distribution (Kentor, 2001). A high GC indicates a higher level of income inequality and a low GC indicates a more equitable distribution of income. This approach is criticised for failing to ascertain the number of people below the PL.

\subsection{Composite Poverty Measures}

This model combines the strengths of the earlier models; the population below the PL and income distribution. Some indices it uses are the Sen Index (S) and the Forster- Geer -Thorbeck Index (FGT). The S Index integrates the Head Count Index, Poverty Gap Index and the GC. The poverty headcount, poverty gap, and severity of poverty are the most common indices integrated in the FGT index (Lugo \& Maasoumi, 2009). A limitation of composite poverty measures is that they are designed to represent and compare living standards across all countries in the world based available data but do not give an in-depth understanding into all relevant indices of development or poverty in the country being studied (De Kruijk \& Rutten, 2007)

\subsection{The Physical Quality of Life Index (PQ LI) and the Augmented Physical Quality of Life Index (AP Q LI)}

This approach focuses on social development issues and uses qualitative measures of social wellbeing instead of income to determine the quality of life. It focuses on three indicators; infant mortality, life expectancy and basic literacy. This index was augmented by incorporating more indicators; health status, women status, defence effort, economy, demography, geography, political participation, cultural diversity and welfare effort in measuring poverty. The quality of life includes both health- related factors, such as physical, functional, emotional, and mental well-being and also non-health-related factors such as jobs and social relationships (Gill \& Feinstein, 1994). This model has been criticised for assigning absolute measures to qualitative factors.

\subsection{Human Development Index}

This combines both income and non-income factors in measuring poverty. It measures the relative degree of deprivation in a country to what is obtained globally. The HDI was developed by the United Nations 
Development Programme (UNDP) 1990 has been used for inter-country comparison to bring the relative achievement of countries on the poverty ladder (Anand, 1994; Noorbakhsh, 1998; Rep, 2006). It focuses on life expectancy, literacy rate and per capita income.

The measurement of Relative Poverty is executed based on average income of a specific percentage of the population that is considered poor with respect to the set income of the general population, and the proportion of the population whose incomes fall short of the predetermined percentage of the mean income in the society. For Subjective Poverty, results obtained from participatory studies on individual perception about poverty are used to measure poverty.

\section{Poverty Theories}

Poverty, as a social phenomenon has attracted the interest of researchers and its reduction programmes are designed in response to theories that justify such interventions. The paradigm of poverty has a direct bearing on the alleviation measures adopted (Bradshaw, 2005). Poverty reduction strategies require an effective assessment and a clear understanding of how key factors affect the welfare status of households, along with other covariates (John C. Anyanwu, 2014). Thus, poverty theories are divergent and resulting in different intervention strategies. This paper analyses poverty in Nigeria through the lenses of the culture of poverty, individual deficiency theory, progressive social theory, geographical disparities theory, cumulative and cyclical interdependence theory, poverty individualisation and the theory of social exclusion /cumulative disadvantage

\subsection{The Culture of Poverty}

This concept was developed by Oscar Lewis, an American anthropologist as a result of his studies of the urban poor in Mexico and Puerto Rico. It constitutes a pattern of life, which people adopt as a community, and is passed from one generation to the next. People adopt a fatalistic attitude that leaves them feeling marginalized, helpless and inferior. Family life is characterised by high divorce rates, with mother, children often abandoned. Individuals do not participate in community life by engaging in voluntary associations, self-help initiatives and politics (Bradshaw, 2005). They make little use banks, hospitals and other facilities to enhance their welfare and well-being. Perceptions may be influenced by religious or cultural beliefs such that people are not psychologically geared towards taking advantage of changing conditions or available opportunities (Ryan 1976). Harmful practices and values are absorbed and perpetuated from generation to generation.

The Culture of Poverty is prevalent in developing countries and societies in the early stages of industrialization as well as among the lower class in advanced capitalist societies. It is a reaction to low income and lack of opportunities such that people live for the present and believe in luck rather than effort to achieve success. The culture can be eroded if the causes are removed

In Nigeria, weak governance, impunity, systemic failures, illiteracy, income inequality, unemployment and corruption have entrenched this culture manifesting in poor orientation, low standard of living, and high rate of social ills, political unrest and abuse of religion. Politicians and government officials tend to be selfish, greedy and corrupt, enriching themselves by looting from the common wealth of the country. Corruption in Nigeria has a long history and has been a subject of discourse by many analysts (Aluko, 2002; Dike, 2005; Enakhimion, 2011; Hope Sr, 2017; Ogbeidi, 2012; Ogundiya, 2009; Okoosi-Simbine, 2011; Osoba, 1996; Salisu, 2000; Tignor, 1993). Unfortunately, the public is unenlightened and gullible to shallow intellectualism and sentimentalism allowing corruption and its fruits to thrive (Oshewolo, 2010). There tends to be no accountability in public and community service. Greed and selfishness seem to be embedded in the psyche of an average Nigerian in leadership position. Funds meant for development are mismanaged and embezzled by corrupt government officials. Good values and hard work are unrewarded and ill-gotten wealth is lauded and celebrated. Indiscipline, bribery and corruption, extortion, nepotism and tribalism are acceptable norms in every sphere (Smith, 2010). The rule of law is abused and structures of checks and balances are manipulated to the advantage of the privileged few. Politics is perceived as a very lucrative venture and an opportunity to become rich or relevant rather than a call to service. It is characterized by 'godfatherism', imposition of unpopular candidates and sycophancy. Ewhrudjakpor (2008) notes that Nigeria is socio-economically backward even with her abundant oil wealth and 70 percent of her population is still under the scourge of poverty and recommends that government must legislate against inappropriate behaviour and corruption of government officials to overcome poverty. This culture is also manifested in the slow transition from the analogue to the digital economy in developing countries, (Nigeria inclusive) where access to and adoption of the facilities of information and communication technology such as the internet, broadband, mobile money etc. is poor (World Development Report 2016 Working Version, 2015). Often times, this is as a result of a warped mentality caused by cultural and religious inhibitions where people are negatively influenced to oppose westernization and secularism to avoid erosion of societal values, 
norms and culture. All these negative behaviours impact on the how resources are distributed in Nigeria and contribute to the high incidence of poverty in Nigeria. Based on this theory, poverty can be overcome if deliberate and genuine reorientation is imbibed or commonly adopted, otherwise, this culture will continue in a vicious cycle and be passed on from one generation to the next inflicting poverty on the population.

\subsection{Individual Deficiency Theory}

This theory attributes poverty to individual deficiencies. The poor are assumed to be responsible for creating their problems through lack of hard work and bad choices. Other variations to this theory ascribe poverty to lack of certain genetic attributes, intelligence and even punishment from God for sins committed.

Neo- classical economists reinforce individualistic sources of poverty with the assumption that individuals are responsible for their choices in maximizing their wellbeing through wise investment. The theory cast the poor as a moral hazard with claims that poverty persist because the poor are not doing enough or are engaged in activities which are counterproductive (Gwartney \& McCaleb,1985). Poverty reduction is achievable through skills acquisition, hard work, motivation and resilience.

This can be applicable in the context of poverty analysis in Nigeria. Poverty has been aggravated by failure of individuals to take responsibility for their destinies in order to have a brighter future. Failure of individuals to acquire adequate skills and training could lead to loss of career opportunities and result in poverty. In analysing how individuals make wrong choice which inflict poverty, Dike (2009, p. 130) explains that the wrong attitude and mentality towards technical and vocational subjects by youths in Nigeria makes them " lack the skills and knowledge to compete effectively in the rather tight labour market and thus loiter around in the villages and cities from dawn to dusk looking for jobs that are not available". Non- enrolment in schools, laziness, indiscipline and engagement in crime and other social ills are personal choices that could result in poverty for individuals. Such could have far reaching adverse effects on an individual's household as the economic status of parents have a strong impact on the opportunities and academic performance of their children (Osonwa, Adejobi, Iyam, \& Osonwa, 2013). Poverty induced by individual deficiencies can be allevi ated if all stakeholders including government and policy makers provide the needed support; opportunities and incentives that help people make right choices to evade poverty.

\subsection{Progressive Social Theory}

Proponents of this theory do not view individuals as the source of poverty but economic, political and social distortions as well as discrimination, which limit opportunities and resources to create wealth and overcome poverty. The 19th century social theorists waged a full attack on the individual theory of poverty by exploring how social and economic systems overrode and created individual poverty situations. They analyse how the economic system of capitalism created a reserve army of the unemployed as a deliberate strategy to keep wages low (Bradshaw, 2005). They argue that people may work hard and have acceptable attitudes but still be in the poverty trap because of dysfunctional social and economic systems.

The theory ascribes poverty to economic, social and political structures that make the poor fall behind regardless of how committed they may be. Another category of system flaws associated with poverty relates to groups of people being discriminated against based on personal attributes such as race, gender, disability and religion, which limit their opportunities in spite of their personal capabilities.

In Nigeria, government policies and actions exacerbate poverty. These may be adopted in pursuit of good intentions, but poor implementation could impoverish the citizens. The SAP and its various fallouts in the form of massive devaluation of the Naira, high inflation, factory closures, privatization, commercialization, appropriate pricing of petroleum products and unlimited free market contributed to the poverty situation. The political economy of Nigeria has contributed immensely to the level of poverty in the country. There is strong correlation between the character of governance and the degree of poverty in Nigeria (Omoyibo, 2013). Onyishi and Ezeibe (2014, p. 2) further explain that:

In Nigeria, after the attainment of flag independence, ubiquitous state involvement in the emergent national economy took on even greater dimension. The incipient oil-economy provided further impetus as the resources available to the public multiplied almost geometrically. State power and positions were now increasingly seen as the most viable and rapid avenues for acquisition of private capitals. Thus, state positions offered greater attraction to Nigerians, as experience had shown that they became the surest means to riches, affluence and prestige in the Nigerian society. To this extent, state power became wealth and wealth an efficacious pathway to power.

The structure of Nigeria's economy has also worsened the poverty situation. Its productive base is narrow and 
undiversified with the economy largely dependent on oil revenue while other critical sectors are neglected. This situation has hampered economic growth and capacity utilization leading to macroeconomic instability and poverty. Inadequate provision of social and economic infrastructure by government has also led to deterioration of the standard of living and contributed to poverty in Nigeria. Failure to invest in the power sector resulting in high cost of production and high prices of locally manufactured goods has led to collapse of the manufacturing sector. Similarly, the country has lost her international market share in agricultural exports due to neglect and removal of incentives that drive growth in the agricultural sector. Nigeria has great potential for massive job creation, expansion of markets and industrialization given her human and natural resources but remains limited by structural distortions and lack of the will to bring about progressive change on the part of successive governments. Misplacement of priorities by governments at all levels manifesting in wasteful expenditure rather than investment in critical sectors that have direct bearing on the standard of living, has aggravated poverty in Nigeria.

Policies relating to empowerment of women and equal rights for the disabled have contributed to poverty. Bias, discrimination on the basis of ethnicity and religion, and non-adherence to principles of true federalism and federal character in appointments and projects distribution have led to many ethno-religious conflicts and social unrests in Nigeria resulting in wanton destruction of lives and property thereby worsening the poverty situation of the country.

\subsection{Geographical Disparities Theory}

This theory focuses on poverty in geographical perspective e.g. rural poverty, ghetto poverty, southern poverty, third world poverty etc. It calls attention to the fact that people, institutions and cultures in certain areas lack access to opportunities for wealth creation. This theory is closely linked to the economic agglomeration theory which shows how the concentration of similar firms attract supportive services and markets which further attracts more firms while impoverished communities generate more poverty, low housing prices in such areas attract more people. This type of poverty can be addressed through community development distressed locations where poverty is rampant (Bradshaw, 2005).

This theory is applicable in the Nigerian context where poverty is prevalent in some geographical locations: rural areas, slums and areas prone to natural disasters such as floods, draught and desert encroachment. The level of economic activities is low leading high rates of unemployment and other manifestations of poverty. The gross neglect of rural areas in the provision of social amenities and empowerment opportunities by successive governments have led to an imbalance and a wide divide between rural and urban dwellers resulting in challenges of rural -urban drift. Poverty is high because governments and communities have not tapped the resources and opportunities in the disadvantages areas to improve the wellbeing of the populations. And so, food shortages, housing crisis, low electricity (power) generation, fuel crisis and other deprivations persist in a country well-endowed with vast and arable land, rivers, waterfalls, mineral deposits and other resources that could yield immense benefits if properly utilized. Populations in disadvantaged areas live in sub-human conditions and are afflicted with poverty and absence of opportunities to escape it.

\subsection{Cyclical Interdependence Theory}

The theory builds on the components of the other theories of poverty. It has its origin in the works of Myrdal (1957) who developed a theory of interlocking circular interdependence within a process of cumulating causation that explains economic development and underdevelopment. He analyses how personal and community welfare are closely linked in a cascade of negative Consequences-Lack of employment opportunities can lead to emigration, closing of retails stores, decline in local tax revenues, deterioration of schools, poorly trained workers, inability of firms to adopt cutting edge technology and lack of incentives to attract new firms which leads to greater unemployment and continues in a vicious cycle of poverty. For an individual, unemployment leads to low consumption, low spending, low savings and investments, loss of self-confidence, weak motivation and depression etc. One problem leads to multiple problems and generate poverty.

In Nigeria, unemployment is a key causal factor of poverty Nigeria and its steady increase spells calamity for her citizens. With an unemployment rate of $10.4 \%$ in Q4 2015, a total of 22.45 million individuals in the Nigerian labour force are either unemployed or underemployed (National Bureau of Statistics, 2016). Consequently, there is a high dependency ratio which puts a lot of strains and pressure on the privileged few who may indulge in corrupt practices to meet up with family and societal expectations. This in turn leads to inefficiency in productivity, lack of accountability, poor service delivery and low performance and eventually lead to systemic failures and aggravating poverty in the country. There is therefore an intertwining of factors where one problem leads to another and eventually engulfs the entire country affecting everyone directly or indirectly. 


\subsection{Poverty Individualisation}

The concept of poverty was developed by Beck based on the German experience (Bak \& Larsen, 2015). It is a recent theory which challenges the traditional theories was are largely based on class division. Beck's analysis offers an explanation on the paradox in which "the patterns of social inequality have remained relatively stable yet the living conditions of the population have changed dramatically"(Beck, 1992, p. 91). Thus, the class society has given way to the individualised society where individual behaviour is now less connected to norms and values in a traditional sense and less dependent on collective identity in terms of social class (Bak \& Larsen, 2015). This implies that people are leading individualistic lives with their distinct identities; therefore, poor people are a heterogeneous group (many faces of poverty). On this basis, the theory has three verifiable propositions namely; poverty democratisation, poverty temporalisation and poverty biographisation,

The theory of poverty democratisation infers that many people are affected by the scourge of poverty in varying degrees but are not equally vulnerable to it. It is an individual experience affecting so many people simultaneously. Temporalisation implies that poverty is experienced on a temporary basis; short-term, medium, long single period or repeated period in a life time. There is a time dimension to the experience of poverty. Biographisation links poverty to certain life events and biographical transitions in life e.g. period of ill health, divorce, single parenthood, job hunting etc.

The structure of poverty in Nigeria also validates this theory as statistics on employment by National Bureau of Statistics (2016) show categorisation of unemployed persons on the basis of age groups, educational qualifications and occupation. Unemployment has a strong correlation with poverty, and so it provides an evidence and explanation for the structure of poverty in Nigeria. The nature of poverty in Nigeria is complex and multidimensional as posited by this theory. There is no single strategy or framework that could lead to its eradication because experiences, belief and value systems differ across the country. There are causal factors of poverty that can be addressed as isolated cases and others that require a holistic approach with consideration of individual circumstances, prevailing environmental factors and social realities.

\subsection{Theory of Social Exclusion/Cumulative Disadvantage}

The concept of poverty has been redefined and broadened in recent years to cover other spheres of human existence. Hence, from the 1990s, the European Union has focused on the term 'social exclusion' to encompass other forms of deprivations or denial of rights, goods and services, and the inability to participate in the normal relationships and activities, available to the majority of people in a society, whether in economic, social, cultural or political arenas (Levitas et al., 2007, p. 9). Marlier and Atkinson (2010) relate the concept of social exclusion to the lack of voice, power, and representation whereby individuals and groups are involuntarily barred from political, economic, and social activities, preventing their full involvement in the society in which they live. Labonté, Hadi, and Kauffmann (2011) define it as a situation in which people are deprived from participating in economic, social, political and cultural activities at a level considered to be normatively acceptable. Social exclusion focuses less on the state than on the processes leading to it, primarily a lack of: material resources (social necessities) income to acquire such necessities and/or state subsidies for their provision access to formal labour markets access to affordable/adequate housing access to educational and health care opportunities freedom from discrimination opportunities for social participation (social networks) power or voice to affect the policy choices of governments influencing all of the above conditions. A review of existing social exclusion frameworks, indicators and measures led to identification of nine principle domains that capture processes of social exclusion/inclusion: employment and work income and economic resources material resources education and skills health housing social resources community resources personal safety

In their study, Gallie, Paugam, and Jacobs (2003, p. 1) found that poverty leads to a vicious circle of social exclusion. They observe that unemployment makes people vulnerable to poverty, and poverty in turn makes it more difficult for people to return to work thereby increasing the risk of social isolation. Income generated from a productive activity determines one's level of poverty and is a significant measure of the degree of isolation, stigmatization and sense of belonging to a community (Stewart et al., 2009). While social exclusion is being associated with unemployment and level of income Gallie et al. $(2003$, p. 1) however notes that these are dependent on socio-cultural factors such as household structure and patterns of local sociability in different contexts.

The perspectives of poverty based on the theory of social exclusion dwell on cumulative disadvantage whereby a comfortable majority co-exist with a disadvantaged minority who are collectively excluded from socio-economic opportunities in the society. It runs contrary to the individualisation perspective, which views poverty as a relatively transient and individualistic phenomenon or experience. The individualisation theory views poverty as 
a phenomenon, which occurs independent of traditional stratification factors (Layte \& Whelan, 2002, p. 209).

In applying both perspectives to the nature of poverty in Nigeria, there are evidences to show how poverty ravages socially excluded people (e.g. People living with disability, rural/slum dwellers) and how poverty is experienced at an individual level. Both perspectives appear to be valid in understanding the manifestations of poverty in Nigeria.

\section{Conclusion}

The theories of poverty examined in this paper, reflect the conceptualization of poverty in Nigeria. They offer an insight into the factors that could lead to poverty. Policy makers and executors may do well to make an in-depth and comprehensive analysis of the poverty status of citizens before designing programmes to address their challenges. Having reviewed these theories of poverty, this paper corroborates the fact that poverty is a complex and multidimensional phenomenon because it encompasses economic, social, cultural and psychological indicators. It requires a hydra-headed approach in tackling its menace. It is pertinent to have an understanding of underlying causal factors of poverty in designing pro-poor programmes that will effectively and progressively lead to its reduction in a given context. Perhaps, empowering people to develop resilience to cope with it and eventually overcome it within the scope of their resources and capabilities can only reduce it.

\section{References}

Abimiku, A. C. (2006). An appraisal of Poverty Alleviation Programmes in Nigeria: A Case Study of Benue, Nasarawa and Plateau State 1986-2003.

Abimuku, A. C. (2006). Review of concept and measurement of poverty. Journal of Contemporary Issues on Poverty, l(1).

Aigbokhan, B. E. (1998). The impact of adjustment policies on income distribution in Nigeria: An empirical study. Development Policy Centre.

Aigbokhan, B. E. (2008). Growth, inequality and poverty in Nigeria. Prepared for United Nations Economic Commission for Africa (UNECA). Addis Ababa, Ethiopia.

Ajakaiye, D., \& Adeyeye, V. (2001). Concepts, measurement and causes of poverty. Central Bank of Nigeria Economic and Financial Review, 39(4), 8-44.

Alesina, A., \& Perotti, R. (1996). Income distribution, political instability, and investment. European economic review, 40(6), 1203-1228. https://doi.org/10.1016/0014-2921(95)00030-5

Aluko, M. (2002). The institutionalization of corruption and its impact on political culture and behaviour in Nigeria. Nordic Journal of African Studies, 11(3), 393-402.

Anand, S. (1994). Human development index: methodology and measurement.

Anyanwu, J. C. (1992). President Babangida's structural adjustment programme and inflation in Nigeria. Journal of Social Developfnimt in Africa, 7, 1-5.24.

Anyanwu, J. C. (1997). Poverty in Nigeria: Concepts, measurement and determinants. Poverty alleviation in Nigeria, 93-120.

Anyanwu, J. C. (2014). Marital Status, Household Size and Poverty in Nigeria: Evidence from the 2009/2010 Survey Data. African Development Review, 26(1), 118-137. https://doi.org/10.1111/1467-8268.12069

Arisi-Nwugballa, E. A., Elom, M. E., \& Onyeizugbe, C. U. (2016). Evaluating the relevance of Entrepreneurial Orientation to the Performance of Micro, Small and Medium Enterprises in Ebonyi State, Nigeria. International Journal of Academic Research in Accounting, Finance and Management Sciences, 6(3), 221-230.

Atkinson, A. B. (1970). On the measurement of inequality. Journal of Economic Theory, 2(3), 244-263. https://doi.org/10.1016/0022-0531(70)90039-6

Backwith, D. (2015). Social Work, Poverty and Social Exclusion. Maidenhead, Berkshire: McGraw-Hill Education.

Bak, C. K., \& Larsen, J. E. (2015). Social exclusion or poverty individualisation? An empirical test of two recent and competing poverty theories. European Journal of Social Work, 18(1), 17-35. https://doi.org/10.1080/13691457.2013.878316

Barrientos, A., \& Hulme, D. (2016). Social protection for the poor and poorest: Concepts, policies and politics. Springer. 
Beck, U. (1992). Risk society: Towards a new modernity. London: Sage Publications Ltd.

Beegle, K., Christiaensen, L., Dabalen, A., \& Gaddis, I. (2016). Poverty in a rising Africa. World Bank Publications. https://doi.org/10.1596/978-1-4648-0723-7

Bhalla, A. S., \& Lapeyre, F. (2016). Poverty and exclusion in a global world. Springer.

Bradshaw, J., \& Main, G. (2016). Child poverty and deprivation. The Wellbeing of Children in the UK, 31.

Callan, T., \& Nolan, B. (1991). Concepts of poverty and the poverty line. Journal of Economic Surveys, 5(3), 243-261. https://doi.org/10.1111/j.1467-6419.1991.tb00134.x

Chen, S., \& Ravallion, M. (2007). Absolute poverty measures for the developing world, 1981-2004. Proceedings of the National Academy of Sciences, 104(43), 16757-16762. https://doi.org/10.1073/pnas.0702930104

Commins, P. (2004). Poverty and social exclusion in rural areas: characteristics, processes and research issues. Sociologia Ruralis, 44(1), 60-75. https://doi.org/10.1111/j.1467-9523.2004.00262.x

Dauda, R. S. (2017). Poverty and Economic Growth in Nigeria: Issues and Policies. Journal of Poverty, 21(1), 61-79. https://doi.org/10.1080/10875549.2016.1141383

De Kruijk, H., \& Rutten, M. (2007). Weighting dimensions of poverty based on peoples priorities: Constructing a composite poverty index for the Maldives. Q-squared working paper, 35.

Deaton, A. (2002). Is world poverty falling? Finance and Development, 39.

Dike, V. E. (2005). Corruption in Nigeria: A new paradigm for effective control. Africa Economic Analysis, 24(08), 1-22.

Dike, V. E. (2009). Addressing youth unemployment and poverty in Nigeria: A call for action, not rhetoric. Journal of Sustainable Development in Africa, 11(3), 129-151.

Elumilade, D., Asaolu, T., \& Adereti, S. (2006). Appraising the institutional framework for poverty alleviation programmes in Nigeria. International Research Journal of Finance and Economics, 3(9), 66-77.

Enakhimion, L. I. (2011). Corruption In Nigeria.

Ewhrudjakpor, C. (2008). Poverty and its alleviation: The Nigerian experience. International Social Work, 51(4), 519-531. https://doi.org/10.1177/0020872808090245

Feagin, J. R. (1972). Poverty: We still believe that God helps those who help themselves. Psychology today, 6(6), $101-110$.

Foster, J. E. (1998). Absolute versus relative poverty. The American Economic Review, 88(2), 335-341.

Gallie, D., Paugam, S., \& Jacobs, S. (2003). Unemployment, poverty and social isolation: Is there a vicious circle of social exclusion? European Societies, 5(1), 1-32. https://doi.org/10.1080/1461669032000057668

Gastwirth, J. L. (1972). The estimation of the Lorenz curve and Gini index. The review of economics and statistics, 306-316. https://doi.org/10.2307/1937992

Gastwirth, J. L., \& Glauberman, M. (1976). The interpolation of the Lorenz curve and Gini index from grouped data. Econometrica: Journal of the Econometric Society, 479-483. https://doi.org/10.2307/1913977

Gill, T. M., \& Feinstein, A. R. (1994). A critical appraisal of the quality of quality-of-life measurements. Jama, 272(8), 619-626. https://doi.org/10.1001/jama.1994.03520080061045

Grootaert, C. (1995). Structural change and poverty in Africa: A decomposition anakysis for Côte d'Ivoire. Journal of Development Economics, 47(2), 375-401. https://doi.org/10.1016/0304-3878(95)00018-L

Hope Sr, K. R. (2017). Corruption in Nigeria Corruption and Governance in Africa (pp. 125-162). Springer. https://doi.org/10.1007/978-3-319-50191-8_4

Ihonvbere, J. O. (1993). Economic crisis, structural adjustment and social crisis in Nigeria. World Development, 2l(1), 141-153. https://doi.org/10.1016/0305-750X(93)90142-V

Jencks, C. (1992). Rethinking social policy: Race, poverty, and the underclass: Harvard University Press Cambridge, MA.

Kentor, J. (2001). The long term effects of globalization on income inequality, population growth, and economic development. Social Problems, 48(4), 435-455. https://doi.org/10.1525/sp.2001.48.4.435 
Labonté, R. N., Hadi, A., \& Kauffmann, X. E. (2011). Indicators of Social Exclusion and Inclusion: A Critical and Comparative Analysis of the Literature. Population Health Improvement Research Network.

Laderchi, C. R., Saith, R., \& Stewart, F. (2003). Does it matter that we do not agree on the definition of poverty? A comparison of four approaches. Oxford development studies, 31(3), 243-274. https://doi.org/10.1080/1360081032000111698

Laderchi, C. R., Saith, R., \& Stewart, F. (2006). Does the definition of poverty matter? Comparing four approaches. Poverty in focus, 10-11.

Layte, R., \& Whelan, C. T. (2002). Cumulative Disadvantage Or Individualisation? A Comparative Analysis Of $\begin{array}{lllll}\text { Poverty Risk And Incidence. European } & \text { Societies, }\end{array}$ https://doi.org/10.1080/14616690220142790

Levitas, R., Pantazis, C., Fahmy, E., Gordon, D., Lloyd, E., \& Patsios, D. T. (2007). The Multidimensional Analysis Of Social Exclusion. A Research Report For The Social Exclusion Task Force. Bristol.

Lewis, O. (1971). The culture of poverty. Poor Americans: How the white poor live, 20-26.

Lipton, M. (1980). Migration from rural areas of poor countries: the impact on rural productivity and income distribution. World Development, 8(1), 1-24. https://doi.org/10.1016/0305-750X(80)90047-9

Lok-Dessallien, R. (1999). Review of poverty concepts and indicators. UNDP Soc Dev Poverty Elimin Div Poverty Reduct Ser. Retrieved from http://www.undp.orgpovertypublicationspovReview pdf

Lugo, M. A., \& Maasoumi, E. (2009). Multidimensional poverty measures from an information theory perspective. Citeseer.

Marlier, E., \& Atkinson, A. B. (2010). Indicators of poverty and social exclusion in a global context. Journal of Policy Analysis and Management, 29(2), 285-304. https://doi.org/10.1002/pam.20492

Myrdal, G. (1968). Asian drama, an inquiry into the poverty of nations. Asian drama, an inquiry into the poverty of nations.

National Bureau of Statistics. (2016). Unemployement/under-employment report Q4 2015.

Noorbakhsh, F. (1998). A modified human development index. World Development, 26(3), 517-528. https://doi.org/10.1016/S0305-750X(97)10063-8

Ogbeidi, M. M. (2012). Political leadership and corruption in Nigeria since 1960: A socio-economic analysis. Journal of Nigeria Studies, 1(2).

Ogundiya, I. S. (2009). Political corruption in Nigeria: Theoretical perspectives and some explanations. Anthropologist, 11(4), 281-292. https://doi.org/10.1080/09720073.2009.11891117

Okoosi-Simbine, A. T. (2011). Corruption in Nigeria State, Economy, and Society in Post-Military Nigeria (pp. 157-180). Springer. https://doi.org/10.1057/9780230117594_7

Omoyibo, K. U. (2013). Leadership, Governance, and Poverty in Nigeria (Vol. 4). https://doi.org/10.5901/mjss.2013.v4n6p29

Onyishi, A., \& Ezeibe, C. (2014). Governance and Enthronement of Poverty in Nigeria. Arts and Social Sciences Journal, 5(2). https://doi.org/10.4172/2151-6200.100067

Oshewolo, S. (2010). Galloping poverty in Nigeria: an appraisal of government interventionist policies. Journal of Sustainable Development in Africa, 12(6), 264-274.

Osoba, S. O. (1996). Corruption in Nigeria: historical perspectives. Review of African Political Economy, 23(69), 371-386. https://doi.org/10.1080/03056249608704203

Osonwa, O., Adejobi, A., Iyam, M., \& Osonwa, R. (2013). Economic status of parents, a determinant on academic performance of senior secondary schools students in Ibadan, Nigeria. Journal of Educational and Social Research, 3(1), 115-122.

Pearson, T. (2015). Poverty: The Other Risk Factor for Diabetes and Its Complications. AADE in Practice, 3(2), 8-10. https://doi.org/10.1177/2325160315572597

Porter, J. R., \& Washington, R. E. (1979). Black identity and self-esteem: A review of studies of Black $\begin{array}{lllll}\text { self-concept, } 1968-1978 . \quad \text { Annual Review of } & \text { Sociology, }\end{array}$ https://doi.org/10.1146/annurev.so.05.080179.000413

Rep, D. (2006). Human development index. 
Room, G. (2016). 'New Poverty'in the European Community. Springer.

Salisu, M. (2000). Corruption in Nigeria.

Shah, M. K. (2016). The myth of community: Gender issues in participatory development. ITGD Publishing.

Smith, D. J. (2010). A culture of corruption: Everyday deception and popular discontent in Nigeria. Princeton University Press.

Stewart, M. J., Makwarimba, E., Reutter, L. I., Veenstra, G., Raphael, D., \& Love, R. (2009). Poverty, Sense of Belonging and Experiences of Social Isolation. Journal of Poverty, 13(2), 173-195. https://doi.org/10.1080/10875540902841762

Thornton, P. K., Jones, P. G., Owiyo, T., Kruska, R., Herrero, M., Kristjanson, P., . . Omolo, A. (2006). Mapping climate vulnerability and poverty in Africa.

Tignor, R. L. (1993). Political corruption in Nigeria before independence. The Journal of Modern African Studies, 31(2), 175-202. https://doi.org/10.1017/S0022278X00011897

World Development Report 2016 Working Version. (2015). World Development Report 2016: Internet for Development.

\section{Copyrights}

Copyright for this article is retained by the author(s), with first publication rights granted to the journal.

This is an open-access article distributed under the terms and conditions of the Creative Commons Attribution license (http://creativecommons.org/licenses/by/4.0/). 